\title{
Robot-assisted laparoscopic versus retroperitoneal endoscopic donor nephrectomy: a matching analysis
}

\author{
Minh Sam Thai ${ }^{1}$ Quy Thuan $\mathrm{Chau}^{2}$, Khac Chuan Hoang ${ }^{2}$, Xuan Thai Ngo ${ }^{1}$, Trong Hien Nguyen², Kinh Luan Thai ${ }^{1}$, \\ Le Quy Van Dinh², Duc Minh Pham¹, Thanh-Tuan Nguyen ${ }^{1}$ \\ 1Department of Urology, Cho Ray Hospital, University of Medicine and Pharmacy at Ho Chi Minh City, Ho Chi Minh City, Vietnam
${ }^{2}$ Department of Urology, Cho Ray Hospital, Ho Chi Minh City, Vietnam
}

Background: This study aims to assess safety and efficacy of introducing robotic-assisted laparoscopic donor nephrectomy (RALDN) to the standard retroperitoneal endoscopic living donor nephrectomy (RELDN).

Methods: Data were collected prospectively from 124 consecutive living kidney donors ( 93 for RELDN subgroup and 31 for RALDN subgroup) from February 2018 to December 2020. Donor baseline demographics, perioperative outcomes and recipient outcomes were recorded, and these parameters were compared between the two subgroups before and after propensity-score matching.

Results: For the entire group, mean age was $51.1 \pm 9.1$ years; $42.7 \%$ were males; mean body mass index was $22.7 \pm 2.4 \mathrm{~kg} / \mathrm{m}^{2}$; and there were 109 left kidneys (88\%). The following data of RELDN and RALDN was respectively recorded: operative time (213 \pm 43 vs. $216 \pm 39$ minutes, $P=0.721)$, warm ischemic time ( $4.7 \pm 1.2$ vs. $4.9 \pm 1.4$ minutes, $P=0.399)$, postoperative complications ( $5.4 \%$ vs. $6.5 \%, P=1)$, hemoglobin $(\mathrm{g} / \mathrm{L})$ drop $(9.4 \pm 7.2$ vs. $9.7 \pm 6.6, \mathrm{P}=0.836)$, donor blood creatinine at 1 month $(1.17 \pm 0.25 \mathrm{vs} .1 .12 \pm 0.25 \mathrm{mg} /$ $\mathrm{dL}, \mathrm{P}=0.325)$ and at 6 month $(1.15 \pm 0.23$ vs. $1.13 \pm 0.24 \mathrm{mg} / \mathrm{dL}, \mathrm{P}=0.734)$. In post-propensity score matched analyses, there was significant differences between the two groups including opioid use after surgery $(48.4 \%$ vs. $16.1 \%, P=0.014)$ and postoperative hospital stays ( $2.7 \pm 1.5$ vs. $3.8 \pm 2.2$ day, $P=0.02)$.

Conclusions: RALDN could be safely introduced into a living donor program experienced in laparoscopic donor nephrectomy.

Corresponding author: Thanh-Tuan Nguyen

E-mail: thanhtuan0131@gmail.com

(c) The Korean Society for Transplantation

This is an Open Access article distributed under the terms of the Creative Commons Attribution Non-Commercial License (http://creativecommons.org/licenses/by-nc/4.0/) which permits unrestricted non-commercial use, distribution, and reproduction in any medium, provided the original work is properly cited. 